\title{
KEKERASAN DALAM PACARAN PADA REMAJA PEREMPUAN
}

\author{
Fenita Purnama Sari Indah ${ }^{1 *}$, Nur Hasanah ${ }^{2}$, Putri Handayani Setyaningsih ${ }^{3}$, Rita Dwi \\ Pratiwi ${ }^{4}$, Lela Kania Rahsa Puji ${ }^{5}$ \\ ${ }^{1,2,5}$ STIKes Kharisma Persada, Jl. Pajajaran No 1, Tangerang Selatan 15417, Indonesia \\ ${ }^{2,4}$ STIKes Widya Dharma Husada Tangerang, J1. Pajajaran No 1, Tangerang Selatan 15417, Indonesia
}

\begin{tabular}{|c|c|}
\hline ARTICLE INFORMATION & $A B S T R A C T$ \\
\hline $\begin{array}{l}\text { *Corresponding Author } \\
\text { Fenita Purnama Sari Indah } \\
\text { E-mail: fenita.purnama@masda.ac.id }\end{array}$ & $\begin{array}{l}\text { Sexual violence against women is the most common } \\
\text { form of violence against women in dating relationships. The } \\
\text { highest number of perpetrators of sexual violence in the realm of } \\
\text { personal relationships is boyfriends with the largest reporting of }\end{array}$ \\
\hline $\begin{aligned} & \text { Keywords: } \\
& \text {. } \\
& \text { - } \text { Gating violence; } \\
& \text { - } \text { Knowledge; } \\
& \text { - } \text { Attitude }\end{aligned}$ & $\begin{array}{l}\text { girls. This study used a quantitative approach, with a cross } \\
\text { sectional design. The research sample was } 150 \text { respondents at } \\
\text { SMK Sasmita Jaya } 1 \text {, South Tangerang City. The results showed } \\
\text { that } 61 \text { respondents }(40.6 \%) \text { had poor knowledge, } 137 \\
\text { respondents }(91.3 \%) \text { had poor attitudes, and } 5 \text { girls who had } \\
\text { experienced violence in dating }(3,3 \%) \text {. The results of statistical } \\
\text { tests showed that there was no relationship between knowledge } \\
\text { and violence in dating ( } p \text {-value }=0.068>0.05) \text { and there was no } \\
\text { relationship between attitudes and violence in dating (p-value = } \\
\text { 0.359>0.05). Suggestions to the next researchers are that it is } \\
\text { better to explore more factors related to dating violence, for } \\
\text { example self image factors, self efficacy and others. }\end{array}$ \\
\hline $\begin{aligned} & \text { Kata Kunci: } \\
& \text { - } \text { Kekerasan dalam pacaran; } \\
& \text { - } \text { Remaja perempuan; } \\
& \text { - } \text { Pengetahuan; } \\
& \text { - } \text { Sikap }\end{aligned}$ & $\begin{array}{l}\text { Kekerasan seksual terhadap perempuan adalah bentuk } \\
\text { kekerasan terhadap perempuan terbanyak dalam hubungan } \\
\text { pacaran. Angka tertinggi kategori pelaku kekerasan seksual } \\
\text { dalam ranah relasi personal merupakan pacar dengan pelaporan } \\
\text { terbesar } 1.528 \text { kasus. Tujuan penelitian ini untuk menganalis } \\
\text { Pengetahuan, sikap, dan tindakan Kekerasan Dalam Pacaran } \\
\text { yang diterima oleh remaja perempuan. Penelitian ini } \\
\text { menggunakan pendekatan kuantitatif, dengan rancangan cross } \\
\text { sectional. Sample penelitian berjumlah } 150 \text { reponden di SMK } \\
\text { Sasmita Jaya 1, Kota Tangerang Selatan. Hasil penelitian } \\
\text { diperoleh bahwa pada remaja perempuan, pengetahuan yang } \\
\text { kurang baik sebanyak } 61 \text { responden }(40,6 \%) \text {, sikap yang kurang } \\
\text { baik sebanyak } 137 \text { responden ( } 91,3 \%) \text {, remaja perempuan yang } \\
\text { pernah mendapat tindakan kekerasan dalam pacaran sebanyak } 5 \\
\text { responden }(3,3 \%) \text {. Hasil uji statistik diperoleh bahwa tidak ada } \\
\text { hubungan pengetahuan dengan kekerasan dalam pacaran ( } p \text { - } \\
\text { value=0,068>0,05) dan tidak ada hubungan sikap dengan } \\
\text { kekerasan dalam pacaran ( } p \text {-value }=0,359>0,05) \text {. Saran kepada } \\
\text { peneliti selanjutnya yaitu sebaiknya menggali lebih banyak lagi } \\
\text { faktor-faktor yang berhubungan dengan kekerasan dalam } \\
\text { pacaran, misalnya faktor self image, self efficacy dan faktor } \\
\text { lainnya. }\end{array}$ \\
\hline
\end{tabular}




\section{PENDAHULUAN}

Pada kasus yang ditangani lembaga mitra pengadalayanan terdapat $71 \%$ (11.719 kasus) yang terjadi di ranah personal. Dari 11.719 kasus di ranah personal, 64\% atau 7.548 kasus berupa kekerasan terhada istri, $21 \%$ atau 2.507 kasus kekerasan dalam pacaran, $7 \%$ atau 844 kasus kekerasan terhadap anak perempuan, dan 6\% atau 667 kasus kekerasan dalam relasi personal lain. Kekerasan fisik masih menempati urutan tertinggi pada tahun 2013, yaitu mencapai 4.631 (39\%), di urutan kedua kekerasan psikis 3.344 (29\%), kekerasan seksual 2.995 (26\%), dan kekerasan Ekonomi mencapai 749 (6\%). Dari aspek pekerjaan atau profesi korban di ranah personal paling banyak adalah Ibu Rumah Tangga, pelajar, dan karyawan swasta (Komnas Perempuan, 2013) (Komnas Perempuan, 2014).

\section{Berdasarkan catatan tahunan} komisi nasional perempuan 2017, disebutkan bahwa 19\% kekerasan diranah rumah tangga atau relasi personal adalah kekerasan dalam pacaran, menempati peringkat ke 3 dengan jumlah 1.873 kasus. Angka tertinggi kategori pelaku kekerasan seksual dalam ranah relasi personal merupakan pacar dengan pelaporan terbesar 1.528 kasus. Besar jumlah angka tercermin dalam kasus yang nyata terjadi dilingkup masyrakat. Kasus dan data yang ada membuktikan kekerasan dalam pacaran adalah permasalahan serius yang harus segera di tangani.
Kekerasan dalam pacaran atau KDP merupakan perilaku kasar, agresif, dan membatasi dalam sebuah hubungan pacaran. Secara umum, kekerasan dalam pacaran di bagi menjadi tiga yaitu fisik, emosional (psikis) dan seksual. Sumber lain mencantumkan kategori tambahan yaitu kekerasan ekonomi seperti melarang bekerja dan memanfaatkan keuangan pribadi pasangan

Komisi Nasional Anti kekerasan terhadap perempuan (komnas perempuan) kekerasan seksual adalah bentuk kekerasan terhadap perempuan terbanyak dalam hubungan pacaran. Menurut catatan komnas perempuan, dari 2.073 kasus kekerasan yang di laporkan ke institusi pemerintahan sepanjang 2018, sebanyak 1.750 kasus adalah kekerasan dalam pacaran.

Sejumlah penelitian mengungkapkan, betapa besar dampak perilaku kekerasan terhadap kesehatan perempuan. Selain sangat mengguncang psikologis dan kesehatan fisik korban. Kekerasan dalam pacaran memiliki banyak dampak pada kesehatan reproduksi. Sejumlah kasus mengindikasikan secara jelas bahwa perempuan korban kekerasan sangat potensial mengalami berbagai bentuk PMS (penyakit menular seksual) mulai dari yang ringan sampai yang berat dan juga kemungkinan terkena HIV/AIDS. Kekerasan dalam pacaran juga dapat berakibat pada terganggunya organ kesehatan reproduksi pada korban. Kekerasan dalam pacaran 
mengakibatkan kehamilan pra nikah, selain berdampak pada negatif perempuannya, perbuatan tersebut juga berdampak pada bayi yang akan dilahirkan. Banyak juga korban yang mengalami keguguran. Bahkan korban juga sangat mungkin korban bertingkah laku yang merugikan kesehatan, seperti merokok, dan melakukan hubungan sex yang tidak aman karena rasa benci dan putus asa.

$$
\text { Pada data BKKBN (Badan }
$$

Kependudukan dan Keluarga Berencana Nasional) tahun 2013, sebanyak 46 persen remaja usia 15-19 tahun sudah melakukan hubungan seksual sebelum menikah (BKKBN, 2013)
. Dengan data yang perlu di tangani dengan serius, peneliti ingin melakukan penelitian data di SMK Sasmita Jaya di Tangerang Selatan agar dapat mengetahui masih adakah kekerasan dalam pacaran yang belum terlaporkan walaupun belum ada pasal khusu untuk KDP tetapi di dalam KDP banyak unsur penganiayaan di bawah RUU KHUP

\section{METODE}

Penelitian ini menggunakan pendekatan kuantitatif, dengan rancangan cross sectional. Sample penelitian berjumlah 150 reponden di SMK Sasmita Jaya 1, Kota Tangerang Selatan..

\section{HASIL}

Pengetahuan tentang Kekerasan dalam Pacaran

Tabel 1. Pengetahuan tentang Kekerasan dalam Pacaran

\begin{tabular}{ccc}
\hline $\begin{array}{c}\text { Pengetahuan tentang } \\
\text { Kekerasan dalam } \\
\text { Pacaran }\end{array}$ & Frekuensi & Persentase (\%) \\
\hline Kurang baik & 61 & 40,6 \\
Baik & 89 & 59,3 \\
Total & 150 & 100 \\
\hline
\end{tabular}

Sumber : Data Primer, 2019

Berdasarkan data pada tabel 1. dapat pengetahuan kurang baik sebanyak 61 diketahui bahwa responden yang memiliki responden $(40,6 \%)$.

\section{Sikap tentang Kekerasan dalam Pacaran}

Tabel 2. Sikap tentang Kekerasan dalam Pacaran

\begin{tabular}{ccc}
\hline $\begin{array}{c}\text { Sikap tentang } \\
\text { Kekerasan dalam } \\
\text { Pacaran }\end{array}$ & Frekuensi & Persentase (\%) \\
\hline Kurang baik & 137 & 91,3 \\
Baik & 13 & 8,6 \\
Total & 150 & 100 \\
\hline
\end{tabular}

Sumber Data : Data Primer, 2020

Berdasarkan data pada tabel 2. memiliki sikap kurang baik sebanyak 137 dapat diketahui bahwa responden yang responden $(91,3 \%)$. 
Kekerasan dalam Pacaran

Tabel 3. Kekerasan dalam Pacaran

\begin{tabular}{ccc}
\hline $\begin{array}{c}\text { Kekerasan dalam } \\
\text { Pacaran }\end{array}$ & Frekuensi & Persentase (\%) \\
\hline Ya & 5 & 3,3 \\
Tidak & 145 & 96,6 \\
Total & 150 & 100 \\
\hline
\end{tabular}

Sumber : Data Primer, 2019

Berdasarkan data pada tabel 3 dapat

mengalami kekerasan dalam pacaran diketahui bahwa responden yang pernah sebanyak 5 responden $(3,3 \%)$.

\section{Hubungan Pengetahuan dengan Kekerasan Dalam Pacaran Pada Remaja Perempuan}

Tabel 4. Hubungan Pengetahuan dengan Kekerasan Dalam Pacaran Pada Remaja Perempuan

\begin{tabular}{|c|c|c|c|c|c|c|c|c|}
\hline \multirow{3}{*}{$\begin{array}{l}\text { Pengetahuan } \\
\text { kekerasan } \\
\text { pacaran }\end{array}$} & \multirow{3}{*}{$\begin{array}{r}\text { tentang } \\
\text { dalam }\end{array}$} & \multicolumn{4}{|c|}{ kekerasan dalam pacaran } & \multirow{2}{*}{\multicolumn{2}{|c|}{ Total }} & \multirow{3}{*}{ p-value } \\
\hline & & & Baik & & ang baik & & & \\
\hline & & $\mathbf{N}$ & $\%$ & $\mathbf{n}$ & $\%$ & $\mathbf{n}$ & $\%$ & \\
\hline Baik & & 88 & 98,88 & 1 & 1,12 & 89 & 100 & 0,068 \\
\hline Kurang baik & & 57 & 93,44 & 4 & 6,65 & 61 & 100 & \\
\hline
\end{tabular}

Berdasarkan tabel 4 dapat diketahui dari 89 Responden dengan Pengetahuan tentang Kekerasan Dalam Pacaran Baik diantaranya bersikap kekerasan dalam pacaran buruk yaitu sebanyak 1 Responden (1,12\%). Responden dengan pengetahuan kekerasan dalam pacaran buruk dari 61 responden diantaranya bersikap kekerasan dalam pacaran buruk 4 (6,59\%). Hasil uji statistik dengan chisquare dengan derajat kepercayaan 95\% di dapat $p$-value 0,068 pada $\alpha=0,05$ dan nilai dapat disimpulkan bahwa tidak ada hubungan pengetahuan dengan kekerasan dalam pacaran pada siswa SMK Sasmita Jaya 1 Tahun 2019 ( $p$ value $=0,068>0,05$ ).

Tabel 5 Hubungan Sikap dengan Kekerasan dalam Pacaran Pada Remaja Perempuan

\begin{tabular}{|c|c|c|c|c|c|c|c|}
\hline \multirow{3}{*}{$\begin{array}{l}\text { Sikap } \\
\text { kekerasan } \\
\text { pacaran }\end{array}$} & \multicolumn{4}{|c|}{ kekerasan dalam pacaran } & \multirow{2}{*}{\multicolumn{2}{|c|}{ Total }} & \multirow{3}{*}{$p$-value } \\
\hline & \multicolumn{2}{|c|}{ Baik } & \multicolumn{2}{|c|}{ Kurang baik } & & & \\
\hline & $\mathbf{N}$ & $\%$ & $\mathbf{N}$ & $\%$ & $\mathbf{N}$ & $\%$ & \\
\hline Baik & 12 & 92.31 & 1 & 7,69 & 13 & 100 & 0,35 \\
\hline Kurang baik & 133 & 97,08 & 4 & 2,92 & 137 & 100 & \\
\hline
\end{tabular}


Berdasarkan tabel 5 dapat diketahui 13 Responden dengan Sikap tentang Kekerasan Dalam Pacaran Baik diataranya bersikap kekarasan dalam pacaran Buruk yaitu sebanyak 1 Responden (7,69\%). Respon dengan sikap tentang Kekerasan Dalam Pacaran Buruk dari 137 Responden diantaranya bersikap Buruk yaitu sebanyak 4 Responden (2,92\%). Hasil uji statistik dengan chi-square dengan derajat kepercayaan $95 \%$ di dapat $p$-value 0,359 pada $\alpha=0,05$ dan nilai dapat disimpulkan bahwa tidak ada hubungan sikap dengan KDP tentang kekerasan dalam pacaran pada siswa SMK Sasmita Jaya 1 Tahun 2019 ( $p$ value $=0,359>0,05)$.

\section{PEMBAHASAN}

Hubungan Pengetahuan dengan

Kekerasan Dalam Pacaran Pada

Remaja Perempuan

Pengetahuan

(knowledge)

didefinisikan sebagai informasi dan pemahaman tentang suatu topik tertentu atau hal-hal umum yang ada di sekitar kita yang biasanya didapat dari pengalaman atau proses pembelajaran. Hal ini sejalan dengan pendapat Surajiyo (2007). Yang menjabarkan pengetahuan sebagai suatu istilah yang dipergunakan untuk menuturkan apabila seseorang mengenal sesuatu atau hasil tahu manusia terhadap sesuatu.
Tidak semua pengetahuan merupakan ilmu pengetahuan. Hanya pengetahuan yang telah tersusun secara sistematik serta diperoleh dengan menggunakan metode ilmiahlah yang disebut dengan ilmu pengetahuan. Oleh karena itu, pengetahuan senantiasa bertujuan untuk mendapatkan kepastian serta menghilangkan prasangka akibat dari adanya ketidakpastian. Hal ini sesuai dengan tujuan pengetahuan teoritikal menurut Henle. Yaitu memahami kenyataan dan merenungkan kebenaran.

Berdasarkan tabel 4 dapat diketahui dari 89 Responden dengan Pengetahuan tentang Kekerasan Dalam Pacaran Baik diantaranya bersikap kekerasan dalam pacaran buruk yaitu sebanyak 1 Responden (1,12\%). Responden dengan pengetahuan kekerasan dalam pacaran buruk dari 61 responden diantaranya bersikap kekerasan dalam pacaran buruk 4 (6,59\%). Hasil uji statistik dengan chi-square dengan derajat kepercayaan $95 \%$ di dapat $p$-value 0,068 pada $\alpha=0,05$ dan nilai dapat disimpulkan bahwa tidak ada hubungan pengetahuan dengan kekerasan dalam pacaran pada siswa SMK Sasmita Jaya 1 Tahun 2019 ( $p$ value $=0,068>0,05)$.

Penelitian tersebut sejalan dengan penelitian Izati bahwa tidak terdapat hubungan antara pengetahuan dengan 
kekerasan dalam pacaran $p$ value $=0,536>$ 0,05. Faktor yang menyebabkan tidak terdapat hubungan pengetahuan dengan KDP tentang kekerasan dalam pacaran salah satu informasi yang diterima merupakan informasi yang masih tabu, belum pernah mendapatkan edukasi dan masih merasa cuek untuk apa mengetahui apa itu tentang kekerasan dalam pacaran. Selain pengethauan, menurut Manchikanti, terdapat banyak hal yang mengakibatkan terjadinya kekerasan dalam pacaran, misalnya trauma di masa lalu. Sebab secara umum, kekerasan pada masa anakanak baik laki-laki maupun perempuan mempengaruhi kekerasan dalam pacaran denga $\mathrm{p}$ value $<0,05$. Hal tersebut menjelaskan bahwa cycle of violence (siklus kekerasan) terjadi di laki-laki maupun perempuan dan tidak memandang gender (Manchikanti, dkk, 2011).

\section{Hubungan Sikap Dengan KDP (Tindakan ) Tentang Kekerasan Dalam}

\section{Pacaran Pada Remaja}

Sikap merupakan kesiapan atau kesedian untuk bertindak dan bukan merupakan pelaksaan motif tertentu, fungsi sikap belum merupakan tindakan (reaksi terbuka) atau aktivitas. Perilaku merupakan respons atu reaksi seseorang terhadap stimulus (rangsangan dari luar). Oleh karena perilaku ini terjadi melalui proses adanya stimulus terhadap organisme, dan kemudian organisme tersebut merespons.Perilaku merupakan hasil dari pada segala macam pengalaman serta interaksi manusia dengan lingkungannya yang terwujud dalam bentuk pengetahuan sikap dan tindakan. Perilaku merupakan respon/reaksi seorang individu terhadap stimulus yang berasal dari luar mauoun dari dalam dirinya (Notoatmojo 2010).

Berdasarkan tabel 5 dapat diketahui 13 Responden dengan Sikap tentang Kekerasan Dalam Pacaran Baik diataranya bersikap kekarasan dalam pacaran Buruk yaitu sebanyak 1 Responden (7,69\%). Respon dengan sikap tentang Kekerasan Dalam Pacaran Buruk dari 137 Responden diantaranya bersikap Buruk yaitu sebanyak 4 Responden $(2,92 \%)$. Hasil uji statistik dengan chisquare dengan derajat kepercayaan $95 \%$ di dapat $p$-value 0,359 pada $\alpha=0,05$ dan nilai dapat disimpulkan bahwa tidak ada hubungan sikap dengan KDP tentang kekerasan dalam pacaran pada siswa SMK Sasmita Jaya 1 Tahun 2019 ( $p$ value $=0,359>0,05)$.

Penelitian tersebut sejalan dengan penelitian Izati (2012) bahwa tidak terdapat hubungan antara pengetahuan dengan kekerasan dalam pacaran $p$ value $=0,764>0,05$. Berdasarkan hasil penelitian menunjukan tidak ada hubungan antara sikap dengan kekerasan dalam 
pacaran. Menurut peneliti remaja yang memiliki sikap buruk yang memandang bahwa kekerasan dalam pacaran seperti mencubit,mengejek,mengekang itu adalah hal sepele yang bukan suatu kekerasan dalam pacaran.

Sikap tidak berhubungan dengan kekerasam dalam pacaran sebab banyak faktor yang mempengaruhi terjadinya kekerasan dalam pacaran, misalnya trauma masa lalu. Menurut Mary, 2013, pada penelitian yang dilakukan pada mahasiswa perempuan, ditemukan bahwa terdapat kekerasan dari orang tua ke anak dengan kekerasan dalam pacaran.

\section{DAFTAR PUSTAKA}

BKKBN. 46 Persen Remaja Terlibat Seks Pranikah, Remaja rentan terhadap godaan, aborsi, dan penyakit seksual. 2014. Available From: URL:

http://www.bkkbn.go.id/ViewBeri ta.aspx?BeritaID=1764. Diakses pada Nov 2019.

Devi, Christianti Noviolieta. 2013. Kekerasan Dalam Pacaran (Studi Kasus pada Mahasiswa yang pernah melakukan Kekerasan dalam Pacaran). https://core.ac.uk/download/pdf/3

\section{KESIMPULAN}

Hasil penelitian diperoleh bahwa pada remaja perempuan, pengetahuan yang kurang baik sebanyak 61 responden (40,6\%), sikap yang kurang baik sebanyak 137 responden $(91,3 \%)$, remaja perempuan yang pernah mendapat tindakan kekerasan dalam pacaran sebanyak 5 responden $(3,3 \%)$. Hasil uji statistik diperoleh bahwa tidak ada hubungan pengetahuan dengan kekerasan dalam pacaran ( $p$ value $=0,068>0,05)$ dan tidak ada hubungan sikap dengan kekerasan dalam pacaran $(p$-value $=0,359>0,05)$.

3513023.pdf Diakses pada Nov 2019.

Izati dan Adi. 2012. Hubungan Pengetahuan Dan Sikap Terhadap Kekerasan Dalam Pacaran Oada Siswa Kelas XI SMA Negeri 113 Jakarta Tahun 2012 [Skripsi]. Fakultas Kesehatan Masyarakat Universitas Indonesia.

Kementrian Pemberdayaan Perempuan Dan Perlindungan Anak. 2018. Waspada Kekerasan Dalam Pacaran.

https://www.kemenpppa.go.id/ind ex.php/page/read/31/1669/waspad a-bahaya-kekerasan-dalam- 
pacaran selasa 02 januari 2019.

Diakses pada Nov 2019

Komnas Perempuan. Lembar Fakta

Catatan Tahunan (CATAHU)

2012 . 2013. Available From:

URL:

http://www.komnasperempuan.or.

id/wp-

content/uploads/2013/03/Lembar-

Fakta-Catahu-2012-_Launching-

7-Maret-2013_.pdf. Diakses pada

Nov 2019.

Komnas Perempuan. Lembar Fakta

Catatan Tahunan (CATAHU)

Kegentingan Kekerasan Seksual:

Lemahnya Upaya Penanganan

Negara Jakarta, 7 Maret 2014.

2014. Available From: URL:

http://www.komnasperempuan.or.

$\mathrm{id} / \mathrm{wp}-$

content/uploads/2014/03/Lembar-

Fakta-Catatan-Tahunan-2013.pdf.

Diakses pada Nov 2019

Manchikanti, A. Testing the cycle of violence hypothesis: child abuse and adolescent dating violence as predictors of intimate partner violence in young adulthood. 2011. Available From: URL: http://cregs.sfsu.edu/wpcontent/uploads/2012/08/addhealt h_violence_authorsversion.pdf.

Diakses pada Nov 2014.

Mary Lee, et al. Exposure to Family Violence and Attachment Styles as Predictors of Dating Violence Perpetration Among Men and Women: A Mediational Model. Journal of Interpersonal Violence. 2013. Available From: URL: http://jiv.sagepub.com/content/earl y/2013/10/01/0886260513504644. Diakses pada Nov 2014.

Yanti, Fitri. 2012. Kekerasan Dalam Berpacaran.

http://repository.unhas.ac.id/bitstr eam/handle/123456789/1594/KE KERASAN\%20DALAM\%20BE RPACARAN-FITRI\%20YANTISOSIOLOGI-

FISIP.pdf?sequence $=2$ Diakses pada Nov 2019. 